\title{
B cells inhibit the antitumor immunity against an established murine fibrosarcoma
}

\author{
ANDREA MAGLIOCO ${ }^{1,2}$, DAMIÁN G. MACHUCA ${ }^{1}$, MARÍA NOEL BADANO $^{3}$, PAULA NANNINI ${ }^{4}$, \\ GABRIELA V. CAMERANO ${ }^{5}$, HÉCTOR COSTA ${ }^{5}$, ROBERTO MEISS ${ }^{6}$, RAÚL A. RUGGIERO ${ }^{1}$, \\ MIRTA GIORDANO $^{4}$ and GRACIELA I. DRAN ${ }^{1}$ \\ ${ }^{1}$ Laboratory of Experimental Oncology, Institute of Experimental Medicine (IMEX), The National Scientific \\ and Technical Research Council (CONICET), National Academy of Medicine, Buenos Aires C1425AUM; \\ ${ }^{2}$ Center for Higher Studies in Social Sciences and Health (CAECIHS), Interamerican Open University (UAI), \\ Buenos Aires C1270AAH; ${ }^{3}$ Laboratory of Experimental Immunology; ${ }^{4}$ Laboratory of Cancer Immunology, IMEX, \\ CONICET, National Academy of Medicine; ${ }^{5}$ IMEX, CONICET, National Academy of Medicine; ${ }^{6}$ Department of \\ Pathology, Institute of Oncology Studies, National Academy of Medicine, Buenos Aires C1425AUM, Argentina
}

Received March 19, 2016; Accepted June 27, 2016

DOI: $10.3892 / \mathrm{ol} .2017 .5810$

\begin{abstract}
Despite the classic role of B cells in favoring the immune response, an inhibitory action of B lymphocytes in tumor immunity has emerged in certain studies. In methylcolanthrene-induced murine fibrosarcoma (MCC), the loss of immunogenicity and the establishment of tolerance are paralleled by systemic immune suppression and the appearance of $\mathrm{B}^{+} \mathrm{IL}-10^{+}$cells in tumor-draining lymph nodes. The present study aimed to assess the role of the $\mathrm{B}^{+} \mathrm{IL}-10^{+}$cell population in the immune evasion and tolerance induced by MCC through the depletion of B cells in mice at various times of tumor progression: Prior to or subsequent to tumor implantation. Tumor growth and immunological parameters were evaluated. B cell depletion prior to tumor inoculum enhanced tumor growth, initiating the onset of the tumor-induced systemic immune response; however, an increase in the $\mathrm{T}$ regulatory cells (Tregs) at the tumor-draining lymph node could account for tumor exacerbation. B cell depletion once the tumor was established resulted in decreased tumor growth
\end{abstract}

Correspondence to: Dr Andrea Maglioco, Laboratory of Experimental Oncology, Institute of Experimental Medicine (IMEX), The National Scientific and Technical Research Council (CONICET), National Academy of Medicine, 3081 Pacheco de Melo Street, Buenos Aires C1425AUM, Argentina

E-mail:magliocoandrea@yahoo.com.ar

Abbreviations: MCC, methylcolanthrene-induced murine fibrosarcoma; Tregs, T regulatory cells; CI, concomitant immunity; LN, lymph node; TDLN, tumor-draining lymph node; TBM, tumor bearing mice; p.i, post tumor inoculation

Key words: B cells, tolerance, regulatory cells, tumor escape, methylcolanthrene-induced murine fibrosarcoma tumor and a delayed onset of tolerance. Additionally, B cell absence exacerbated $\mathrm{T}$ cell dependent-tumor rejection, reduced Tregs and increased cytotoxic $\mathrm{CD}^{+} \mathrm{T}$ cells. In vitro analysis showed a direct effect of $\mathrm{B}$ cells upon $\mathrm{T}$ cell proliferation. In conclusion, B cell depletion exerts opposite effects when performed prior to or subsequent to tumor implantation. In this initially immunogenic tumor, B cell absence would delay the establishment of immunological tolerance probably by unmasking a pre-existing antitumor response. The present findings elucidate the convenience of modulating B cells in the development of future and more effective immunotherapies against cancer.

\section{Introduction}

The role of the host immune system in the control of cancer progression has been assessed for several years; at present, it is vastly accepted that antitumor immunity occurs and that numerous tumors have developed mechanisms to escape immune control, leading to malignant progression (1). The mechanisms responsible for antitumor immunity failure in individuals with cancer include a wide diversity of soluble immunosuppressive factors, including transforming growth factor $\beta$ (TGF $\beta$ ), interleukin 10 (IL-10), reactive oxygen species (ROS), enzymes and inhibitory ligands such as Fas ligand (FasL) or TNF-related apoptosis-inducing ligand, released by tumor cells or by other regulatory cells in the tumor microenvironment (2). The majority of immunotherapies against cancer aim to counteract the action of regulatory cells in order to achieve tumor remission or prevent recurrences; of these, $\mathrm{T}$ regulatory cells (Tregs) have been the major focus of efforts to therapeutically modulate their inhibitory activity $(3,4)$.

B cells have been classically associated with antigen presentation, antibody secretion and $\mathrm{T}$ cell activation during immune responses (5-8). However, in autoimmune diseases, $\mathrm{B}$ cells were demonstrated to exert immune-regulatory roles suppressing cluster of differentiation $(\mathrm{CD}) 4^{+} \mathrm{T}$ cell responses, 
mainly through IL-10 secretion $(9,10)$. Therefore, novel studies focusing on the role of B cells as negative modulators of the antitumor response are currently underway. Evidence that accounts for the role of $\mathrm{B}$ cells in tumor-induced immunosuppression includes the existence of human B cells with a regulatory phenotype in solid tumors (11), the B cell-mediated induction of Tregs expansion (12-14) and the increase of tumor growth (12,15-17).

Methylcolanthrene-induced murine fibrosarcoma (MCC) is a highly immunogenic tumor that elicits an early specific antitumor immune reaction, which is not strong enough to impede tumor growth (18-21). The antitumor response declines at a certain tumor volume $\left(\sim 500 \mathrm{~mm}^{3}\right)$ and disappears comprising a state of tolerance (18-21). Immunological characteristics of MCC and its rapid growth in vivo make it a suitable model to study mechanisms underlying tumor immunity and tumor-induced immunosuppression. Using this model, previous studies have demonstrated that small tumor-bearing mice (TBM) are able to reject a secondary distant implant of the same tumor through a $\mathrm{T}$ cell mediated-reaction, phenomenon known as concomitant immunity (CI) (18). Later, in the tolerogenic stage, $\mathrm{CI}$ is no longer detected and a second tumor implant grows without being rejected (18). MCC growth was also found to induce a series of alterations in the cell composition of tumor-draining lymph nodes (TDLN), including the progressive increase in B cells with the emergence of an IL-10-producing subpopulation $(20,22)$. These results suggest that B cells may be implicated in the downregulation of the antitumor immunity and the establishment of tumor tolerance in the MCC model. The present study examines the role of B cells in the immunological control of the MCC tumor growth.

\section{Materials and methods}

Mice. A total of $255 \mathrm{BALB} / \mathrm{c}$ and AKR mice (age, 2-3 months), inbred at the animal facilities of The Institute of Experimental Medicine, National Scientific and Technical Research Council, National Academy of Science (Buenos Aires, Argentina) were used in the experiments. Mice were housed at $23^{\circ} \mathrm{C}$ and exposed to $12 \mathrm{~h}$ light/dark cycles, with free access to food and water and handled according to the policies of the National Institutes of Health Guide for the Care and Use of Laboratory Animals.

Tumor. The MCC was induced in male BALB/c mice by the subcutaneous implantation of a methylcholanthrene pellet and was maintained by syngeneic transplantation. MCC is an immunogenic murine tumor characterized by an initial immunogenic state (tumor volume, $100-400 \mathrm{~mm}^{3}$ ) followed by a tolerance state (tumor volume, $>500 \mathrm{~mm}^{3}$ ). Tumor size and volume were assessed every 2 days according to the Attia and Weiss formula: Tumor volume $=0.4 \times\left(\mathrm{a} \mathrm{x} \mathrm{b}^{2}\right)$, where $\mathrm{a}$ and $\mathrm{b}$ represent the larger and smaller diameters, respectively.

$B$-cell depletion. The B cell-depleting monoclonal mouse anti-CD20 antibody (clone, 18B12), kindly provided by Biogen Idec (Cambridge, MA, USA), or rat non B cell-depleting immunoglobulin $\mathrm{G}(\mathrm{IgG})$ antibody (catalog. no., 10700; Thermo Fisher Scientific, Inc., Waltham, MA, USA) was injected intraperitoneally $(10 \mathrm{mg} / \mathrm{kg}) 3$ days prior to or 9 days post tumor inoculation (p.i.). Blood samples were collected on day $0,12,16$ and 24 and $\mathrm{CD} 19^{+}$cell presence was analyzed using a FACS flow cytometer (BD Biosciences San Jose, CA, USA) and WinMDI 2.8 software (developed by Joe Trotter). Experiments were performed at various times following antibody administration.

CI assay. For CI experiments, TBM received a second tumor inoculation of $7 \times 10^{5}$ tumor cells in the contralateral flank. The inoculation was performed 12 days p.i. in the group with B cell-depletion prior to the tumor implant, or 18 days p.i. in the group with B cell-depletion following the tumor implant. Tumor rejection was evaluated when the control group (mice with the second tumor implant only) developed tumors. The physical appearance, movement and weight of the mice were evaluated daily and the tumors were assessed for evidence of ulceration and necrosis.

Cells and culture conditions. Inguinal and axillary TDLN from TBM, equivalent lymph nodes (LN) from non TBM and tumor tissues were aseptically excised and mechanically disaggregated in PBS. Tumor-infiltrating lymphocytes (TILs) were obtained after sedimentation with Ficoll-Triyoson $\left(1.099 \mathrm{~g} / \mathrm{cm}^{3}\right)$, as previously described (23). For in vitro assays, single cell suspensions were cultured at $37^{\circ} \mathrm{C}$ and $5 \%$ $\mathrm{CO}_{2}$ atmosphere in complete medium (RPMI-1640; Gibco; Thermo Fisher Scientific, Inc.) containing $10 \%$ fetal bovine serum (Natocor, Córdoba, Argentina) L-glutamine, penicillin/streptomycin/amphotericin B and 2-mercaptoethanol (Gibco; Thermo Fisher Scientific, Inc.).

$\mathrm{CDI}^{+}$and $\mathrm{CD}^{+}$cell purification. For functional assays, $\mathrm{CD} 19^{+} \mathrm{B}$ cells or $\mathrm{CD}^{+} \mathrm{T}$ cells were isolated from $\mathrm{LN}$ or TILs cell suspension, respectively, via cell sorting (FACSAria II; BD Biosciences).

Flow cytometry. Cell suspensions $\left(1 \times 10^{6}\right)$ were incubated with appropriate concentrations of the following monoclonal antibodies (1:100; BD Pharmingen, San Diego, CA, USA): Fluorescein isothiocyanate (FITC) monoclonal rat anti-mouse CD8 $\alpha$ (clone, 53-6.7; catalog no., 553031); FITC monoclonal rat anti-mouse CD4 (clone, H129.19; catalog no., 553651); phycoerythrin (PE) monoclonal rat anti-mouse CD19 (clone, 1D3; catalog no., 553786); PE monoclonal rat anti-mouse interferon- $\gamma$ (IFN- $\gamma$; catalog no., 562020); PE monoclonal rat anti-mouse IL-10 (catalog no., 561060); PE-Cy5.5 monoclonal rat anti-mouse CD45R/B220 (clone, RA3-6B2; catalog no., 552771); and PE-Cy5.5 monoclonal rat anti-mouse CD25 (clone, PC61; catalog no., 551071). Cells were analyzed using a FACS flow cytometer (BD Biosciences) and WinMDI 2.8 software. Irrelevant isotype-matched antibodies were used as controls. The intracellular presence of forkhead box P3 (Foxp3) was detected with PE-rat anti-mouse Foxp3 (clone, FJK-16s; catalog no., 12-5773; eBioscience, Inc., San Diego, CA, USA) and the Foxp3 staining buffer set (eBioscience, Inc.). Following the stimulation of $\mathrm{LN}$ cells $\left(2 \times 10^{6}\right.$ cells $\left./ \mathrm{ml}\right)$ with ionomycin ( $1 \mu \mathrm{g} / \mathrm{ml}$; Sigma-Aldrich; St. Louis, MO, USA) and phorbol 12-myristate 13 -acetate $(50 \mathrm{ng} / \mathrm{ml}$; Sigma-Aldrich) during $6 \mathrm{~h}$ incubation with brefeldin A (eBioscience, Inc.), 
intracellular staining of IFN- $\gamma$ was detected with the monoclonal rat anti-mouse $\mathrm{CD} 8 \alpha$ and $\mathrm{PE}$ monoclonal rat anti-mouse interferon- $\gamma$ antibodies using the Cytofix/Cytoperm and Perm/Wash buffers (BD Pharmingen), according to the manufacturer's protocol.

$B$ cell inhibitory activity in vitro. Balb/c mouse $\mathrm{LN}$ cells $\left(2 \times 10^{5}\right)$ were incubated with $2 \times 10^{5}$ AKR spleen cells treated with mitomycin C (Sigma-Aldrich) for $96 \mathrm{~h}$. The final $18 \mathrm{~h}$-pulse was $1 \mu \mathrm{Curie} /$ well of $\left[{ }^{3} \mathrm{H}\right]$-thymidine (DuPont NEN Research Products, Boston, MA, USA) for a standard allogeneic proliferation. Balb/c mouse B cells $\left(7.5 \times 10^{4}\right)$ isolated by cell-sorting from TBM or non TBM LN were added in co-culture or through a Transwell chamber, in the presence or absence of IL-10 neutralizing antibody ( $5 \mu \mathrm{g} / \mathrm{ml}$; BD Pharmingen) or granzyme B inhibitor (ZAAD CMK; $10 \mu \mathrm{M}$; Enzo Life Sciences, Inc., Farmingdale, NY, USA), from the beginning of the incubation.

Cytotoxicity assay. In vitro cytotoxicity was evaluated through the JAM test $(20,24)$ Briefly, tumor $\mathrm{CD}^{+} \mathrm{T}$ cells isolated by cell sorting were incubated with $\left[{ }^{3} \mathrm{H}\right]$-thymidine-labeled MCC cells $\left(2 \times 10^{4}\right)$ for $8 \mathrm{~h}$. Specific killing was calculated as: Specific killing $(\%)=100 \times(\mathrm{S}-\mathrm{E}) / \mathrm{S}$, where $\mathrm{S}$ is the spontaneous killing and $\mathrm{E}$ is the experimental killing. Normal $\left[{ }^{3} \mathrm{H}\right]$-thymidine-labeled fibroblasts were used as controls.

Statistical analysis. All statistical analysis was performed using GraphPad Prism 3.0 software (GraphPad Software, Inc., La Jolla, CA, USA) and Microsoft Excel 2010 (Microsoft, Redmond, WA, USA). Differences in tumor growth were evaluated by two-way analysis of variance and Bonferroni post-tests (Fig. 1). Differences obtained in flow cytometry phenotyping (Figs. 2, 3 and 4A), cytotoxicity (Fig. 4B) and B cell inhibitory activity through Transwell (Fig. 5A) experiments were all evaluated for significance using the Student's $t$-test. Differences in B cell inhibitory activity in the presence or absence of anti-IL-10 or ZAAD CMK (Fig. 5B and C) were evaluated by one-way ANOVA and Tukey's Multiple Comparison test. $\mathrm{P}<0.05$ was considered to indicate a statistically significant difference $\left({ }^{*} \mathrm{P}<0.05,{ }^{* *} \mathrm{P}<0.01,{ }^{* * *} \mathrm{P}<0.001\right)$.

\section{Results}

Systemic B cell depletion exerts opposite effects during tumor implantation or tumor growth. Previous studies have described that a progressive increase in IL-10-expressing B cells occurs at the TDLN, as a tumor grows and evolves from an immunogenic to a tolerogenic state $(20,22)$. In order to analyze a possible role for B cells in the establishment of tolerance and consequent tumor progression, TBM were depleted of B cells using an anti-CD20 monoclonal antibody, 3 days prior to or 9 days p.i. (Fig. 1). In the TBM, a single administration of anti-CD20 induced a sustained depletion of peripheral blood B cells (Fig. 1A and C). Depletion prior to tumor implantation resulted in increased tumor growth, which became significant at $\sim$ day 15 p.i. $(\mathrm{P}<0.05$; Fig. $1 \mathrm{~B})$. By contrast, depletion performed after tumor implantation induced tumor growth retardation (Fig. 1D). The inhibition of tumor growth began immediately after antibody inoculum and reached significance $\sim 10$ days later $(\mathrm{P}<0.05)$. These results may indicate that $\mathrm{B}$ cells are initially necessary for the occurrence of the antitumor reaction, and are also required for subsequent tumor progression.

Systemic B cell depletion prior to tumor inoculation does not modify the early antitumor response at the TDLN, but enhances Treg number. Lymph node draining the tumor site is the first place where the immune response against tumor development takes place. A previous study showed that the initial growth of MCC could induce the activation of TDLN dendritic and $\mathrm{T}$ cells (immunogenic phase) (20). As the tumor increased in size, the signs of immune activation at TDLN disappeared as the mice became tolerant (tolerogenic phase) (20). On the supposition that B cell depletion prior to tumor implantation could impair the proper onset of the antitumor immune response and thus enhance tumor growth, the TDLN from B cell-depleted TMB were analyzed at various times p.i.. Mice were injected with anti-CD20 or IgG antibodies 3 days prior to tumor inoculum, and the TDLN were excised at days 5 and 20 p.i. and analyzed for cell composition. On day 5, a similar number of total and activated $\mathrm{CD}^{+}$ and $\mathrm{CD}^{+} \mathrm{T}$ cells and $\mathrm{CD} 4^{+} \mathrm{Foxp}^{+}$Tregs were observed in TDLN from the two groups (Fig. 2A). Furthermore, the groups were inoculated with a secondary tumor implant to evaluate the $\mathrm{CI}$, which evaluates the capacity of $\mathrm{T}$ cells to reject a secondary implant (18). The two groups showed the same proportion of tumor rejection $(75 \%)$, suggesting that $\mathrm{B}$ cell depletion did not prevent the early activation stage that occurs in the TDLN following tumor implant. TDLN from depleted and control mice were analyzed on day 20 p.i., when the tumor growth curves of the two groups were clearly separated. An increased number of activated $\mathrm{CD} 8^{+}$and $\mathrm{CD} 4^{+}$ $\mathrm{T}$ cells and increased Tregs were observed in B cell-depleted mice (Fig. 2B).

Systemic B cell depletion once the tumor is established prevents the inhibition of an antitumor response, increases activated T cells and decreases Tregs in TDLN and tumor tissue. Mice were injected with anti-CD20 or IgG antibodies 9 days p.i. and TDLN were excised and analyzed 8 days later. While B cell depletion did not affect the absolute number of $\mathrm{CD}^{+}$and $\mathrm{CD}^{+} \mathrm{T}$ cells, an increase in the number and proportion of activated $\mathrm{CD} 25^{+}-$and IFN- $\gamma$-expressing $\mathrm{CD}^{+}$ $\mathrm{T}$ cells and a decrease in the number and proportion of Tregs was induced (Fig. 3A-F). The subpopulation with putative inhibitory function, B cells expressing IL-10, also decreased $(28,733 \pm 6,294$ vs. $11,533 \pm 2,463 ; n=3 ; P=0.0116)$. At tumor tissue level, B cell depletion induced decreased Treg number and increased $\mathrm{CD} 25^{+} \mathrm{CD} 4^{+}$activated $\mathrm{T}$ cell proportion among CD4 ${ }^{+}$TILs (Fig. 4A). In addition, the functional evaluation of $\mathrm{CD}^{+} \mathrm{T}$ cells isolated from tumors of depleted mice exhibited an increased cytotoxic capacity against MCC cells in culture (Fig. 4B). When CI was evaluated in B cell-depleted mice bearing large tumors $\left(>500 \mathrm{~mm}^{3}\right)$, an increased rate of tumor rejection (80\%) was observed in depleted mice, whereas no rejection was observed in the control IgG-treated group (Chi-square test; $\mathrm{P}=0.00026$ ). This result reinforces the possibility that $\mathrm{B}$ cells may be interfering with $\mathrm{T}$ cell activity. 
A

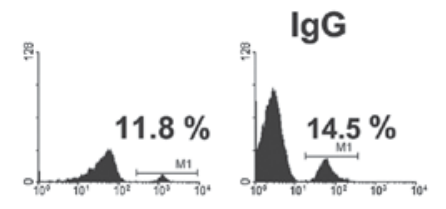

Anti-CD20

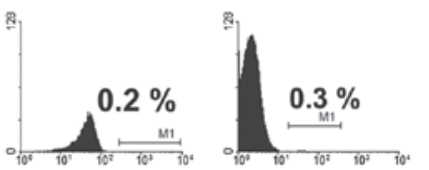

Day 0 p.i.

Day 12 p.i.
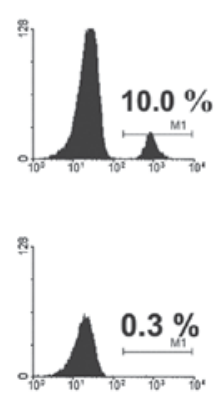

Day 16 p.i.

CD19

C

IgG
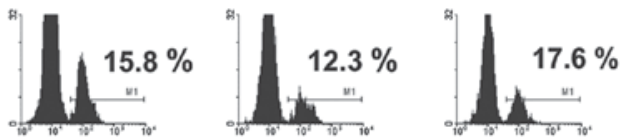

Anti-CD20
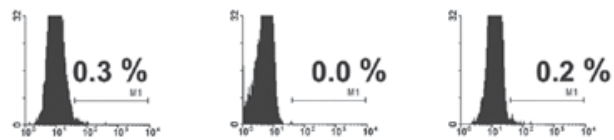

Day 12 p.i.

Day 16 p.i.

Day 24 p.i.

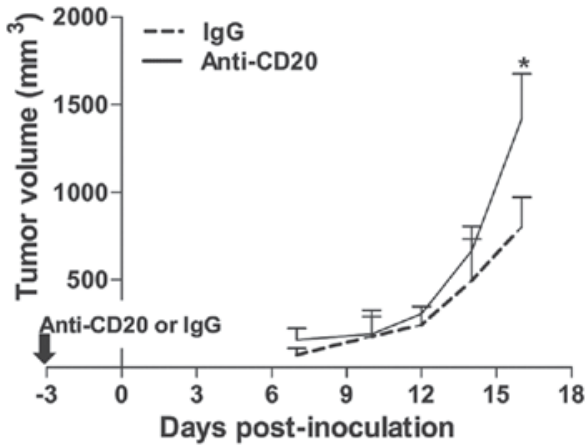

D

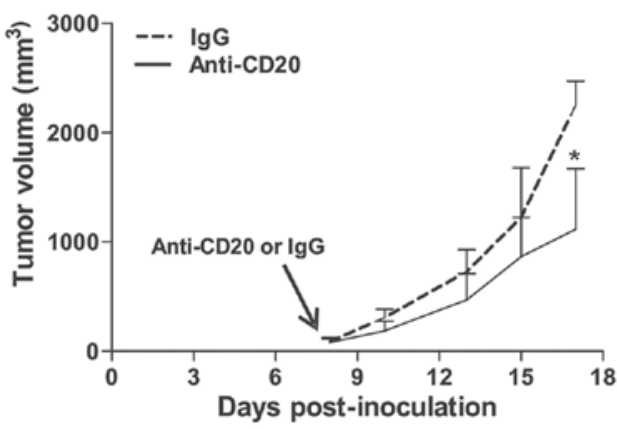

Figure 1. B cell depletion effect on tumor growth. (A) Representative histograms of B cell depletion kinetic in mice treated with anti-CD20 or IgG (control) antibodies, 3 days prior to tumor inoculum. (B) Curves show the effects of B cell depletion on methylcolanthrene-induced murine fibrosarcoma growth in mice treated with anti-CD20 or IgG, 3 days prior to tumor inoculum. (C) Representative histograms of B cell depletion kinetic in mice treated with anti-CD20 or $\mathrm{IgG}$ (control) antibodies, 9 days p.i. (D) Curves show the effects of B cell depletion on methylcolanthrene-induced murine fibrosarcoma growth treated with anti-CD20 or IgG, 9 days p.i. Data from one representative experiment of three; $n=5$ mice per group. ${ }^{~} \mathrm{P}<0.05$. CD, cluster of differentiation; IgG, immunoglobulin G; p.i., post tumor inoculum.
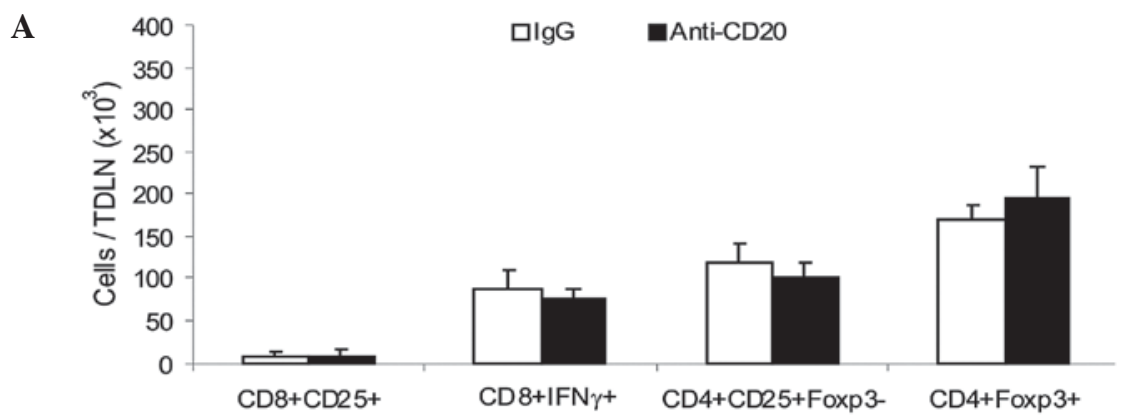

B

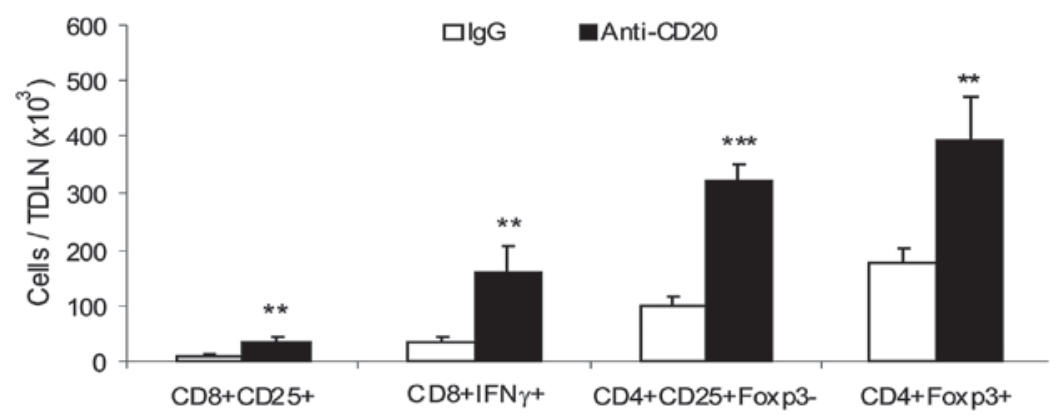

Figure 2. Effect of B cell depletion performed prior to tumor inoculum on $\mathrm{CD} 4^{+}$and $\mathrm{CD} 8^{+} \mathrm{T}$ cell phenotypes in tumor-draining lymph nodes. $\mathrm{B}$ cell depletion was performed 3 days prior to tumor inoculum. Lymph node cells were isolated from TBM or B cell depleted TBM 5 or 20 days p.i.. Cell suspensions were stained with the specific monoclonal antibodies for flow cytometry. Absolute cell number for various cell types was calculated into the nucleated viable cell gate. Bars show the mean of $\mathrm{CD} 8^{+} \mathrm{CD} 25^{+} \mathrm{T}$ cells, $\mathrm{CD} 8^{+} \mathrm{IFN} \gamma^{+} \mathrm{T}$ cells, $\mathrm{CD} 4$ activated $\mathrm{T}$ cells and $\mathrm{T}$ regulatory cell number \pm standard deviation from a representative experiment of three ( $\mathrm{n}=3$ mice per group) at (A) day 5 pi or (B) day 20 pi ( $\mathrm{n}=4-6$ mice per group). ${ }^{* *} \mathrm{P}<0.01,{ }^{* * *} \mathrm{P}<0.001$. CD, cluster of differentiation; TBM, tumor bearing mice; p.i., post tumor inoculum; IFN $\gamma$, interferon $\gamma$; FoxP3, forkhead box P3. 
A

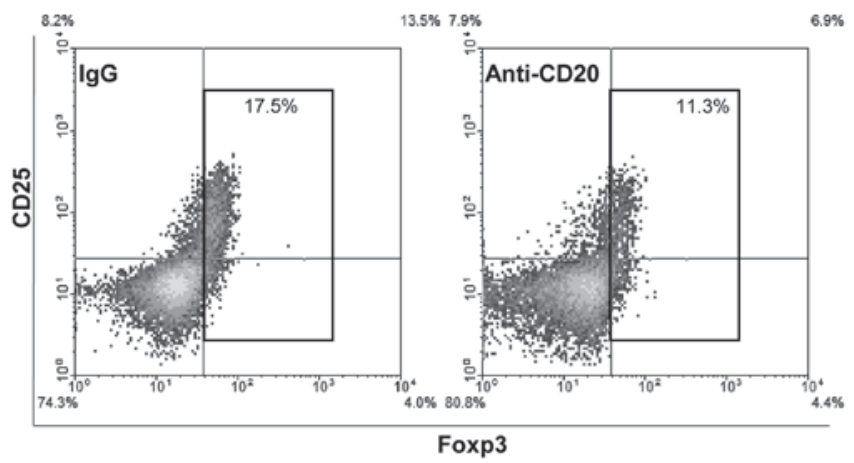

C
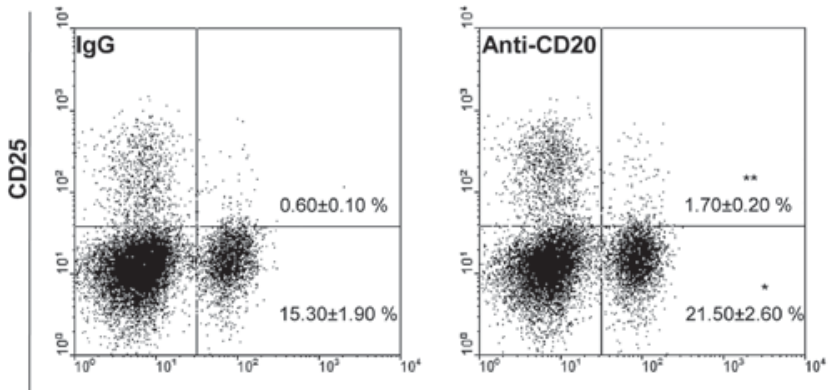

CD8

$\mathbf{E}$
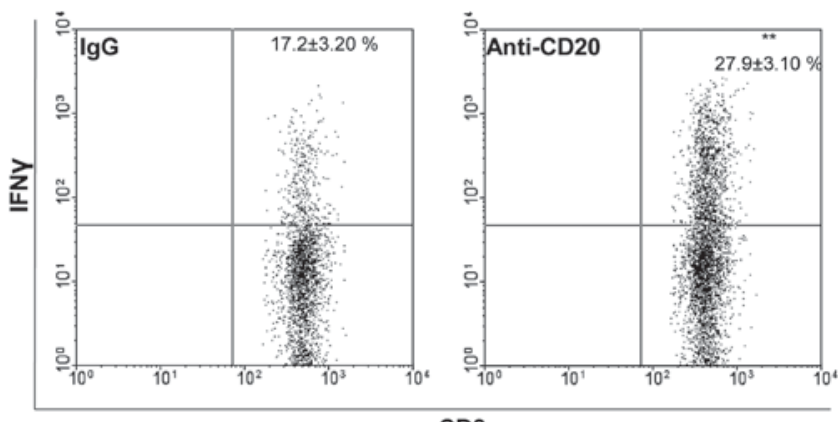

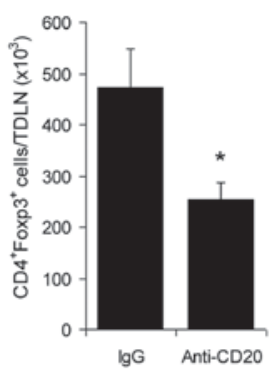

D

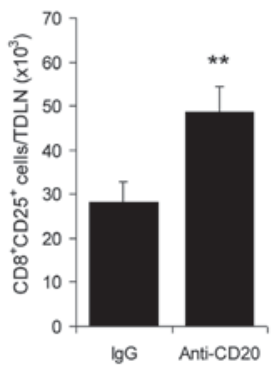

F

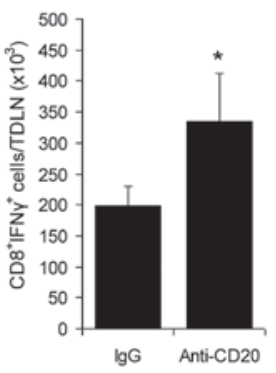

Figure 3. Effect of B cell depletion performed in mice with established tumors on $\mathrm{CD} 4^{+}$and $\mathrm{CD} 8^{+} \mathrm{T}$ cell phenotypes in TDLN. B cell depletion was performed 9 days post tumor inoculum and TDLN were obtained 8 days later. Cell suspensions were stained with specific monoclonal antibodies for flow cytometry. Absolute cell number for various cell types was calculated into the nucleated viable cell gate. (A) Representative dot plots show the percentage of CD4 Tregs $\left(\mathrm{CD} 4^{+} \mathrm{Foxp}^{+}\right)$gated in $\mathrm{CD}^{+} \mathrm{T}$ cells. (B) Bars show the mean Tregs number $\pm \mathrm{SD}$ from a representative experiment of three ( $\mathrm{n}=3$ mice per group). (C) Representative dot plots show the percentage of $\mathrm{CD} 8{ }^{+} \mathrm{CD} 25^{+}$cells. (D) Bars show the mean $\mathrm{CD} 8{ }^{+} \mathrm{CD} 25^{+}$cell number \pm standard deviation from a representative experiment of three ( $\mathrm{n}=3$ mice per group). (E) Representative dot plots show the percentage of CD8 ${ }^{+} \mathrm{IFN}-\gamma^{+}$gated in $\mathrm{CD} 8^{+} \mathrm{T}$ cells after lymph node cells stimulation with phorbol 12-myristate 13-acetate and ionomycin. (F) Bars show the mean CD8 ${ }^{+} \mathrm{IFN} \gamma^{+}$cell number \pm SD from a representative experiment of three ( $\mathrm{n}=3$ mice per group). $\mathrm{P}<0.05,{ }^{* *} \mathrm{P}<0.01 . \mathrm{CD}$, cluster of differentiation; TDLN, tumor-draining lymph nodes; Tregs, $\mathrm{T}$ regulatory cells; FoxP3, forkhead box P3; IFN- $\gamma$, interferon $\gamma$.

A

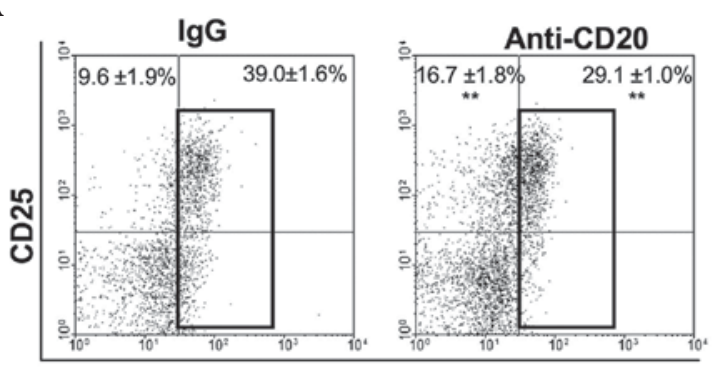

Foxp3
B

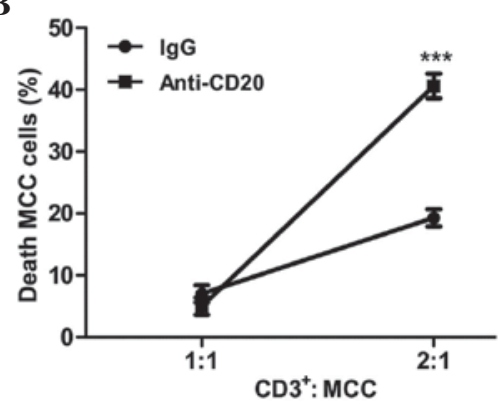

Figure 4. Effect of B cell depletion performed in mice with established tumors on tumor-infiltrating cells. B cell depletion was performed 9 days post tumor inoculum and tumor-infiltrating lymphocytes were isolated from TBM or B cell depleted TBM 8 days later. Cell suspensions were stained with the specific monoclonal antibodies for flow cytometry analysis or cell sorting. (A) Representative dot plots show the percentage of CD $4^{+} \mathrm{T}$ regulatory cells $\left(\mathrm{CD} 4^{+} \mathrm{Foxp} 3^{+}\right)$ and activated $\mathrm{CD}^{+} \mathrm{T}$ cells $\left(\mathrm{CD} 4^{+} \mathrm{CD} 25^{+} \mathrm{Foxp} 3^{-}\right)$gated in $\mathrm{CD} 4^{+} \mathrm{T}$ cells from a representative experiment of three ( $\mathrm{n}=3$ mice per group). (B) The cytotoxic ability of $\mathrm{CD}^{+} \mathrm{T}$ cells isolated from tumor from TBM or B cell depleted TBM was assessed against MCC through JAM test. Representative experiment of three is shown ( $\mathrm{n}=3$ mice per group). ${ }^{* *} \mathrm{P}<0.01,{ }^{* * * *} \mathrm{P}<0.001$. TBM, tumor bearing mice; $\mathrm{CD}$, cluster of differentiation; FoxP3, forkhead box $\mathrm{P} 3$; IgG, immunoglobulin $\mathrm{G}$; MCC, methylcolanthrene-induced murine fibrosarcoma. 
$\mathbf{A}$

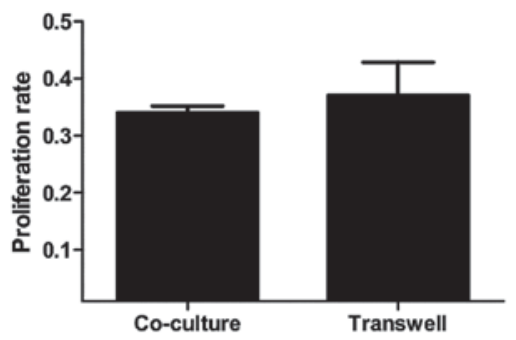

B

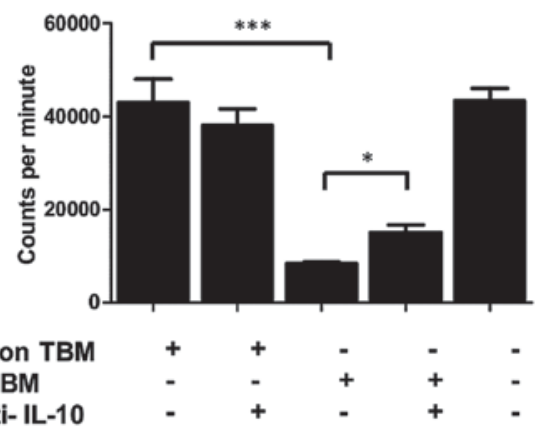

C

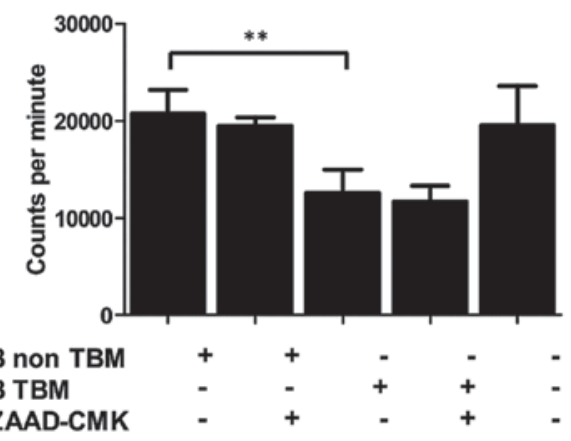

Figure 5. B cells from tumor bearing mice have inhibitory effect in vitro. The ability of B cells to modulate $\mathrm{T}$ cell allogeneic proliferation was evaluated by adding B cells from TBM or non TBM (Balb/c) lymph nodes to a culture of AKR spleen cells (effectors) and Balb/c lymph node cells (target). (A) Bars show the ratio between proliferation detected in the presence of $\mathrm{B}$ cells from TBM and proliferation detected in presence of B cells from non TBM, cultured together or through transwell chamber (data from one representative experiment of two; $n=3$ mice per group). (B) Bars show mean proliferation (counts per minute) \pm standard deviation detected in the presence or absence of anti-IL-10 (data from one representative experiment of three; $n=4$ mice per group). (C) Bars show mean proliferation (counts per minute) \pm standard deviation, detected in the presence or absence of ZAAD-CMK (data from one representative experiment of two; $\mathrm{n}=3$ mice per group). ${ }^{*} \mathrm{P}<0.05$, ${ }^{* *} \mathrm{P}<0.01,{ }^{* * *} \mathrm{P}<0.001$. TBM, tumor bearing mice; IL-10, interleukin-10; ZAAD-CMK, granzyme B inhibitor.

Overall, the results suggest that the absence of B cells could prevent immune suppression, unveiling the antitumor response.

B cells impair $T$ cell activity, partially through IL-10 secretion. A possible inhibitory role of $\mathrm{B}$ cells on $\mathrm{T}$ cell function was further analyzed in vitro. Allogeneic $\mathrm{T}$ cell proliferation was assayed in the presence of B cells isolated from controlor TBM-LN, either with or without allowing cellular contact (Transwell assay). The results indicated that, unlike normal B cells, TBM-derived B cells were able to inhibit lymphocyte proliferation, and that this inhibition did not depend upon cell contact (Fig. 5A). To analyze the possible molecules involved in the inhibition, the same experiment was performed in presence of an IL-10 blocking antibody or a granzyme B inhibitor
(ZAAD-CMK). The B cell-mediated inhibition of T cell proliferation was observed to be partially prevented by the blockade of IL-10 (Fig. 5B), while the inhibition of granzyme B exerted no effect (Fig. 5C). Overall, these results indicate that B cells from TBM have a direct inhibitory effect upon T lymphocyte function that is, at least partially, mediated by IL-10.

\section{Discussion}

Tumor presence generally leads to the appearance of immunosuppressive cell populations that not only affect endogenous antitumor response but weaken the efficacy of immunotherapies $(25,26)$. Although Tregs have been classically assessed as one of the main mediators of tumor-induced immunosuppression $(3,4)$, recent papers described a subset of B cells able to negatively regulate cellular immune responses, mainly through the production of IL-10, in several pathologies including cancer (27-30). The MCC is a highly immunogenic tumor that provokes a strong antitumor immune reaction at the early stages of development. At a certain volume $\left(400 \mathrm{~mm}^{3}\right)$ all systemic humoral and cellular antitumor evidences disappear, and tumor immunogenicity decreases and disappears leading the immune system to a state of tolerance (20). In the MCC model, the immune status of the host is reflected at various levels. During the immunogenic phase, subsequent secondary distant implants of the same tumor are rejected in a T cell-dependent fashion through CI, whereas this capacity is lost in the tolerogenic phase (18). Also, at the TDLN level, the cellular composition of the MCC switches from an activated antitumor profile to a predominantly immunosuppressive environment with immature dendritic cells, Tregs and a marked increase in B cells and IL-10-secreting B cells (20), the latter suggesting B cell involvement in the loss of tumor immunity. The present study aimed to elucidate the role of $\mathrm{B}$ cells in the immune response against MCC and in tumor-induced tolerance, by means of systemic $\mathrm{B}$ cell depletion. To get a close insight in B cell-mediated temporal events, depletion was performed prior to tumor inoculum or subsequent to tumor establishment, when the immune status of the host had clearly changed (20). Notably, opposite effects on tumor growth were obtained. B cell depletion prior to tumor inoculum enhanced tumor growth, suggesting that B cells are initially necessary for the onset of the antitumor response. On the contrary, B cell depletion performed once the immune system had been affected by the growing tumor resulted in decreased tumor growth, suggesting that B cells are also involved in tumor-induced tolerance.

The supposition that B cell absence would impair the initial antitumor response was analyzed through the TDLN cell composition and the CI response. Contrarily to previous expectations, the immune response within TDLN was unchanged in B cell-depleted animals. At day 5 p.i., no differences in activated and regulatory $\mathrm{T}$ cells were observed compared with non depleted TBM. In addition, the two groups displayed comparable rates of CI. Later, on day 20 p.i., when the growth curves in the two groups had clearly separated, an increase in number activated $\mathrm{CD}^{+}$and $\mathrm{CD} 4^{+} \mathrm{T}$ cells, along with an increase in $\mathrm{CD} 4^{+} \mathrm{Foxp} 3^{+}$Tregs were observed in the TDLN of B cell-depleted mice. Speculatively, in the absence of B cells, tumor-induced mechanisms to evade the immune system may involve a compensatory exacerbation of the Tregs 
population, which could explain the separation of the tumor growth curves at that time.

When depletion was performed following the implant of the tumor, TDLN from B cell-depleted animals exhibited an increased number and proportion of IFN- $\gamma$-expressing $\mathrm{CD}^{+}$ $\mathrm{T}$ cells and a decreased number and proportion of Tregs compared with control animals. Also in the tumor tissue, depletion decreased the proportion of Tregs, increased activated CD4 ${ }^{+}$ $\mathrm{T}$ cells and increased the cytotoxic capacity of $\mathrm{CD}^{+} \mathrm{T}$ cells. It is feasible that B cell elimination would prevent or delay the negative impact on the immune system and the induction of regulatory cells induced by the growing tumor. In addition, a remarkable $80 \%$ of $\mathrm{T}$ cell-mediated secondary tumor rejection (CI) was obtained in B cell-depleted mice, whereas no tumor rejection was evidenced in control mice. Overall, these findings suggested that the absence of B cells would extend the immunogenic period, probably by allowing proper $\mathrm{T}$ cell action.

A regulatory role for $B$ cells in cancer immunity that favors tumor progression has previously been assessed in other tumor models. Qin et al (31) demonstrated that low immunogenicity exhibited by a weakly immunogenic breast tumor is associated with B cell presence, while Tadmor et al (12) demonstrated the inhibition of a murine breast tumor and decrease in Tregs in B cell deficient mice. In addition, Shah et al (16) determined that B cells may inhibit an antitumor $\mathrm{T}$ cell-mediated response by antigen nonspecific mechanisms, and Inoue et al (17) showed that robust antitumor cytotoxicity can be developed only in B cell-knockout mice. While these studies have been performed in B cell deficient mice, to the best of our knowledge, only few studies have analyzed a role of B cells in cancer in B cell-depleted animal models. DiLillo et al (8) demonstrated that B cell depletion induced tumor growth exacerbation when performed prior to melanoma implantation; no effect was evidenced when depletion was performed following tumor implantation. These results led the authors to postulate that B cells were required for the onset of $T$ cell activation in the melanoma model, though a promoting action of B cells on tumor growth was not observed (8). In another system Kim et al (15) found that B cell depletion following the establishment of the tumor not only retarded tumor growth but augmented the immunotherapeutic efficacy of a vaccine approach. The results of the present study partially agree with these two studies $(8,15)$. An exacerbation of tumor growth was induced by B cell depletion prior to tumor implant; however, no effects of B cell depletion were detected in two of the recognized markers (activated cells within TDLN and CI) of an immune antitumor reaction in MCC. By contrast, depletion following tumor implantation impaired tumor growth, increased activated $\mathrm{T}$ cells and decreased Tregs. The different time frames in which B cell depletion is performed, the extent of depletion and even the subsets of $B$ cells in various situations may account for these differences.

Multiple regulatory pathways were recently described for B cells in other pathologies, and certain pathways, such as FasL (32) and programmed cell death 1 ligand 2 (33), require cell-to-cell contact to be effective, while others, including TGF $\beta$ (34), granzyme B (11) and IL-10 (13,27,28,35,36), are mediated by soluble molecules secreted by B cells. Accordingly, a previous study reported that B cells expressing IL-10, granzyme B and FasL are present during MCC growth (22). The present study demonstrates that B cells from MCC bearing mice are able to inhibit $\mathrm{T}$ cell proliferation in a contact-independent manner, with IL-10 being partially involved in this inhibition. Our previous results, which indicated a lack of TGF $\beta$ secretion by TDLN cells (20) and the results of the present study which demonstrated no effect of Granzyme B in $\mathrm{T}$ cell proliferation inhibition enable the involvement of these mediators to be ruled out. Future studies are required in order to elucidate whether another nontraditional soluble molecule could be implicated in the inhibition of $\mathrm{T}$ cell proliferation induced by $\mathrm{B}$ cells.

In conclusion, the results of the present study suggest that B cells from MCC bearing mice contribute to tumor-induced immunosuppression and tolerance, favoring tumor progression, by affecting $\mathrm{T}$ lymphocyte function, increasing Treg number at TDLN and preventing $\mathrm{T}$ cell activation and cytotoxicity at the tumor site. Thus, B cell absence creates an imbalance in tumor immunity, which delays the establishment of tolerance and extends the period during which the immune system is able to react against the tumor. The present authors postulate that modulating B cells in a determined time frame could improve immunotherapeutic approaches against cancer.

\section{Acknowledgments}

The present study was supported by grants from the National Institute of Cancer (grant no. 6, ministerial resolution 1006/2016, Argentina), the National Scientific and Technical Research Council (grant no. 11220120100628, Argentina), the National Agency of Scientific Promotion and Technology (grant no 2014-1590, Argentina) and the Alberto J Roemmers Foundation, Argentina. The authors are grateful to Dr Christiane Dosne Pasqualini (National Academy of Medicine, Buenos Aires, Argentina) for a critical discussion of this article.

\section{References}

1. Cavallo F, De Giovanni C, Nanni P, Forni G and Lollini PL: 201: The immune hallmarks of cancer. Cancer Immunol Immunother 60: 319-326, 2011.

2. Rabinovich GA, Gabrilovich D and Sotomayor EM: Immunosuppressive strategies that are mediated by tumor cells. Annu Rev Immunol 25: 267-296, 2007.

3. Petrausch U, Poehlein CH, Jensen SM, Twitty C, Thompson JA, Assmann I, Puri S, LaCelle MG, Moudgil T, Maston L, et al: Cancer immunotherapy: The role regulatory $\mathrm{T}$ cells play and what can be done to overcome their inhibitory effects. Curr Mol Med 9: 673-682, 2009.

4. Rech AJ, Mick R, Martin S, Recio A, Aqui NA, Powell DJ Jr, Colligon TA, Trosko JA, Leinbach LI, Pletcher CH, et al: CD25 blockade depletes and selectively reprograms regulatory $\mathrm{T}$ cells in concert with immunotherapy in cancer patients. Sci Transl Med 4: 134ra62, 2012.

5. LeBien TW and Tedder TF: B lymphocytes: How they develop and function. Blood 112: 1570-1580, 2008.

6. Crawford A, Macleod M, Schumacher T, Corlett L and Gray D: Primary $\mathrm{T}$ cell expansion and differentiation in vivo requires antigen presentation by B cells. J Immunol 176: 349-3506, 2006.

7. Coughlin CM, Vance BA, Grupp SA and Vonderheide RH: RNA-transfected CD40-activated B cells induce functional T-cell responses against viral and tumor antigen targets: Implications for pediatric immunotherapy. Blood 103: 2046-2054, 2004. 
8. DiLillo DJ, Yanaba $\mathrm{K}$ and Tedder TF: B cells are required for optimal CD4+ and CD8+ T cell tumor immunity: Therapeutic B cell depletion enhances B16 melanoma growth in mice. J Immunol 184: 4006-4016, 2010.

9. Fillatreau S, Gray D and Anderton SM: Not always the bad guys: B cells as regulators of autoimmune pathology. Nat Rev Immunol 8: 391-397, 2008.

10. Bouaziz JD, Yanaba K and Tedder TF: Regulatory B cells as inhibitors of immune responses and inflammation. Immunol Rev 224: 201-214, 2008.

11. Lindner S, Dahlke K, Sontheimer K, Hagn M, Kaltenmeier C, Barth TF, Beyer T, Reister F, Fabricius D, Lotfi R, et al: Interleukin 21-induced granzyme B-expressing B cells infiltrate tumors and regulate T cells. Cancer Res 73: 2468-2479, 2013.

12. Tadmor T, Zhang Y, Cho HM, Podack ER and Rosenblatt JD: The absence of B lymphocytes reduces the number and function of T-regulatory cells and enhances the antitumor response in a murine tumor model. Cancer Immunol Immunother 60: 609-619, 2011.

13. Olkhanud PB, Damdinsuren B, Bodogai M, Gress RE, Sen R, Wejksza K, Malchinkhuu E, Wersto RP and Biragyn A: Tumor-evoked regulatory B cells promote breast cancer metastasis by converting resting CD4+ T cells to T-regulatory cells. Cancer Res 71: 3505-3515, 2011

14. Zhang Y, Eliav Y, Shin SU, Schreiber TH, Podack ER, Tadmor T and Rosenblatt JD: B lymphocyte inhibition of antitumor response depends on expansion of Treg but is independent of B-cell IL-10 secretion. Cancer Immunol Immunother 62: 87-99, 2013.

15. Kim S, Fridlender ZG, Dunn R, Kehry MR, Kapoor V, Blouin A, Kaiser LR and Albelda SM: B-cell depletion using an anti-CD20 antibody augments antitumor immune responses and immunotherapy in nonhematopoetic murine tumor models. J Immunother 31: 446-457, 2008.

16. Shah S, Divekar AA, Hilchey SP, Cho HM, Newman CL, Shin SU, Nechustan H, Challita-Eid PM, Segal BM, Yi KH, et al: Increased rejection of primary tumors in mice lacking $\mathrm{B}$ cells: inhibition of antitumor CTL and TH1 cytokine responses by B cells. Int J Cancer 117: 574-586, 2005.

17. Inoue S, Leitner WW, Golding B and Scott D: Inhibitory effects of B cells on antitumor immunity. Cancer Res 66: 7741-7747, 2006.

18. Franco M, Bustuoabad OD, Di Gianni PD, Goldman A, Pasqualini CD and Ruggiero R: A serum- mediated mechanism for concomitant resistance shared by immunogenic and non-immunogenic murine tumors. Br J Cancer 74: 178-186, 1996.

19. Bustuoabad OD, Ruggiero RA, Di Gianni PD, Lombardi G, Beli C, Camerano GV, Dran GI, Schere-Levy C, Costa H, Isturiz MA, et al: Tumor transition zone: A new putative morphological and functional hallmark of tumor aggressiveness. Oncol Res 15: 169-182, 2005

20. Maglioco A, Machuca D, Mundiñano J, Cabrera G, Camicia G, Bruzzo J, Camerano G, Costa H, Ruggiero RA and Dran GI: Lymphadenectomy exacerbates tumor growth while lymphadenectomy plus the adoptive transfer of autologous cytotoxic cells and low-dose cyclophosphamide induces regression of an established murine fibrosarcoma. Cancer Immunol Immunother 60 : 389-399, 2011.
21. Chiarella P, Vulcano M, Bruzzo J, Vermeulen M, Vanzulli S, Maglioco A, Camerano GV, Palacios V, Fernández G, Brando RF, et al: Anti-inflammatory pretreatment enables an efficient dendritic cell-based immunotherapy against established tumors. Cancer Immunol Immunother 57: 701-718, 2008.

22. Maglioco A, Machuca D, Camerano G, Costa H, Ruggiero R and Dran GI: Regulatory B cells presence in lymph nodes draining a murine tumor. Medicina (B Aires) 74: 185-188, 2014.

23. Rosenberg SA, Spiess P and Lafreniere R: A new approach to the adoptive immunotherapy of cancer with tumor-infiltrating lymphocytes. Science 233: 1318-1321, 1986.

24. Matzinger P: The JAM test. A simple assay for DNA fragmentation and cell death. J Immunol Methods 145: 185-192, 1991.

25. Zou W: Regulatory T cells, tumour immunity and imunotherapy. Nat Rev Immunol 6: 295-307, 2006.

26. Whiteside T: Inhibiting the inhibitors: Evaluating agents targeting cancer immunosuppression. Expert Opin Biol Ther 10: 1019-1035, 2010.

27. Mauri C, Gray D, Mushtaq N and Londei M: Prevention of arthritis by interleukin 10-producing B cells. J Exp Med 197: 489-501, 2003.

28. Watanabe R, Ishiura N, Nakashima H, Kuwano Y, Okochi H, Tamaki K, Sato S, Tedder TF and Fujimoto M: Regulatory B cells (B10 cells) have a suppressive role in murine lupus: CD19 and B10 cell deficiency exacerbates systemic autoimmunity. J Immunol 184: 4801-4809, 2010.

29. Matsushita T, Yanaba K, Bouaziz JD, Fujimoto $M$ and Tedder TF: Regulatory B cells inhibit EAE initiation in mice while other B cells promote disease progression. J Clin Invest 118: 3420-3430, 2008.

30. DiLillo DJ, Matsushita T and Tedder TF: B10 cells and regulatory B cells balance immune responses during inflammation, autoimmunity and cancer. Ann N Y Acad Sci 1183: 38-57, 2010.

31. Qin Z, Richter G, Schüler T, Ibe S, Cao X and Blankenstein T: B cells inhibit induction of T cell-dependent tumor immunity. Nat Med 4: 627-630, 1998.

32. Lundy S: Killer B lymphocytes: The evidence and the potential. Inflamm Res 58: 345-357, 2009.

33. Zhong X, Tumang JR, Gao W, Bai C and Rothstein TL: PD-L2 expression extends beyond dendritic cells/macrophages to B1 cells enriched for $\mathrm{V}(\mathrm{H}) 11 / \mathrm{V}(\mathrm{H}) 12$ and phosphatidylcholine binding. Eur J Immunol 37: 2405-2410, 2007.

34. Parekh VV, Prasad DV, Banerjee PP, Joshi BN, Kumar A and Mishra GC: B cells activated by lipopolysaccharide, but not by anti-Ig and anti-CD40 antibody, induce anergy in CD8+ T cells: Role of TGF-beta 1. J Immunol 170: 5897-5911, 2003.

35. Moore KW, De Waal Malefyt R, Coffman RL and O'Garra A Interleukin-10 and the interleukin-10 receptor. Annu Rev Immunol 19: 683-765, 2001.

36. Zheng SG, Wang JH, Gray JD, Soucier H and Horwitz DA Natural and induced CD4+CD25+ cells educate CD4+CD25cells to develop suppressive activity: The role of IL-2, TGF-beta, and IL-10. J Immunol 172: 5213-5221, 2004. 